\title{
Prognostic value of anatomical SYNTAX score in patients with acute ST elevation myocardial infarction undergoing percutaneous coronary intervention for unprotected left main coronary artery
}

\author{
Abdülmelik Yıldız ${ }^{\mathrm{a}}$, Cennet Yıldız ${ }^{\mathrm{b}, *}$, Bayram Bağırtan ${ }^{\mathrm{a}}$, Ahmet Karakurt ${ }^{\mathrm{c}}$ \\ a Avrupa Safak Hospital, Istanbul, Turkey \\ b Tekden Hospital, Istanbul, Turkey \\ c Kafkas University, Kars, Turkey
}

\section{A R T I C L E I N F O}

\section{Article history:}

Received 22 March 2016

Received in revised form 16 May 2016

Accepted 16 May 2016

Available online 20 May 2016

\section{Keywords:}

SYNTAX score

LMCA disease

ST elevation myocardial infarction

\begin{abstract}
A B S T R A C T
Objective: Acute ST-elevation myocardial infarcion (STEMI) due to left main coronary artery (LMCA) disease has high mortality rate. Advancements in stent technology have shown promising results in patients with unprotected left main coronary artery (ULMCA) disease. SYNTAX score (SxS) is recommended to determine appropriate patients for revavascularization with PCI. However, predictive value of SxS in patients with STEMI who underwent primary PCI due to ULMCA disease has not fully been evaluated.

Methods and Results: 53 patients with STEMI who underwent emergent PCI to a culprit LMCA lesion were enrolled in this study. Patients were divided into three groups on the basis of their SxS; low $(\leq 22 ; \mathrm{n}=14)$, intermediate ( $23-32 ; \mathrm{n}=14)$ and high $(\geq 33 ; \mathrm{n}=25)$. During a follow-up of 3 years, SxS exhibited $62.2 \%$ sensitivity and $62.5 \%$ specificity for predicting development of MACE at a cut off value 28.25 (AUC: $0.731, \mathrm{P}=$ 0.008 ), $70 \%$ sensitivity and $66.7 \%$ specificity for predicting mortality at a cut off value 31.25 (AUC:0.675, P = 0.034). At 3-year follow-up, the incidences of mortality, major adverse cardiac events (MACE) and targel vessel revascularization (TVR) were significantly higher in patients with high SxS group than in the intermediate and low SxS groups. In Kaplan-Meier survival analysis, survival rates of the low, intermediate, and high SxS groups were $91.7 \%, 78.6 \%$, and $64.7 \%$, respectively.

Conclusions: Patients with acute STEMI who were treated with emergency PCI to a culprit ULMCA lesion, SxS is an important aid to deciding the appropriate revascularization strategy, can be derived quickly and repeatable. (C) 2016 The Society of Cardiovascular Academy. Production and hosting by Elsevier B.V. All rights reserved. This is an open access article under the CC BY-NC-ND license (http://creativecommons.org/licenses/by-nc-nd/4.0/).
\end{abstract}

\section{Introduction}

Unprotected left main coronary artery (ULMCA) disease occurs in 5\% of patients undergoing coronary angiograpy and is a class I indication for coronary artery bypass graft (CABG) surgery. Acute myocardial infarction (AMI) due to LMCA occlusion has significantly higher rates of mortality than non-culprit LMCA lesion (16.0\% vs. 8.9\%). ${ }^{1}$ In longterm follow-up, patients with LMCA disease have higher rates of cardiogenic shock, target lesion revascularization (TLR) and mortality. ${ }^{2}$ Recent studies have demonstrated that percutaneous coronary intervention (PCI) of the LMCA disease has acceptable in-hospital and long-term mortality rates. The SYNTAX score $(\mathrm{SxS})$ is an angiographic

\footnotetext{
* Corresponding author at: Konaklar mahallesi, Org, İzzettin Aksular cad, Oyak sitesi, 38/2, Beşiktaş, Istanbul, Turkey.

E-mail addresses: drmelik@hotmail.com (A. Yıldız), firdevsi2010@gmail.com, cennet_yildiz@live.com (C. Yıldız), bayrambagirtan2@hotmail.com (B. Bağırtan), karakurt38@hotmail.com (A. Karakurt).

Peer review under responsibility of The Society of Cardiovascular Academy.
}

scoring tool for grading the complexity of the coronary lesion. It can be used to help select optimal revascularization strategy in patients with coronary artery disease. ${ }^{3,4} \mathrm{SxS}$ is an independent predictor of mortality and TVR after PCI. ${ }^{5,6}$ Few studies have evaluated the role of SxS in patients with acute STEMI undergoing primary PCI due to ULMCA disease. The aim of this study was to assess the prognostic value of SxS in predicting in-hospital and long term clinical outcomes among patients who underwent primary PCI for ULMCA lesion.

\section{Methods}

Our single-center, retrospective study included 53 patients with AMI treated with emergency PCI to a culprit ULMCA lesion in our catheterization laboratory between May 2009 and March 2013. Clinical, biochemical, radiological and social data were extracted from the national health data system, telephone contact and outpatient examinations. Patients with protected LMCA disease, renal dysfunction, chronic anemia, instent thrombosis and who underwent emergency CABG surgery were excluded from the study. 
SxS was calculated by summing the total points assigned to each individual lesion identified in the coronary artery with $>50 \%$ luminal obstruction in vessels $>1.5 \mathrm{~mm}$ in diameter. ${ }^{5}$ For the calculation, the soft ware at web site (http://www.syntaxscore.com) was used. On the basis of their SxS, patients were divided into three groups; low ( $\mathrm{SxS} \leq 22$; $\mathrm{n}=14)$, intermediate ( $\mathrm{SxS} 23-32 ; \mathrm{n}=14)$ and high $(\mathrm{SxS} \geq 33 ; \mathrm{n}=25)$.

Angiographic data of the patients were analyzed by 2 interventional cardiologists blinded to the clinical characteristics. In the case of disagreement, a third observer was consulted and a final decision was reached by consensus. Patients received $300 \mathrm{mg}$ of aspirin and a loading dose of (300 to $600 \mathrm{mg}$ ) clopidogrel and intravenous (IV) standard heparin $100 \mathrm{U} / \mathrm{kg}$ (maximal dose $10.000 \mathrm{U}, 60 \mathrm{U} / \mathrm{kg}$ in patients who were treated with glycoprotein IIb/IIla inhibitors) before the procedure. All primary $\mathrm{PCI}$ procedures were performed by femoral approach. The decision on direct or conventional stenting was made by the operator. The LMCA lesion was considered unprotected if there was no patent bypass graft to the left anterior descending (LAD) coronary artery or left circumflex coronary artery (LCX). Acute myocardial infarction (MI) was defined as the presence of typical ongoing ischemic chest pain lasting for more than $30 \mathrm{~min}$ and ST-segment elevation $\geq 1 \mathrm{~mm}$ in 2 contiguous leads or a new left bundle branch block on the initial electrocardiogram. Reinfarction was defined as a recurrent typical chest pain with new electrocardiogram changes and a further increase in enzyme levels (twice the upper limit of normal reference range or any rise by $50 \%$ of the lowest recovery enzyme level). Target Lesion Revascularization (TLR) was defined to be any repeat revascularization with $\mathrm{PCI}$ or $\mathrm{CABG}$ within the stent, or within the 5 -mm borders proximal or distal to the stent. Revascularization was considered as successful treatment of a new lesion in the epicardial vessel. All deaths, including cardiac deaths, were assessed and ascertained by national databases. Major adverse cardiovascular events (MACE) were defined as all-cause mortality, new myocardial infarction and repeat revascularization.

\section{Statistical analysis}

Continuous variables were expressed as the mean + standard deviation and categorical variables were expressed as number (percentage). Group means for continuous variables were compared through 1-way analysis of variance. Likewise, categorical variables were compared by using chi-square test. The Cox proportional hazard model was applied to relate the SX score and long term mortality, reinfarction, revascularization, and overall major adverse cardiac event (MACE). Multivariate analysis was applied separately for all outcomes and overall MACE. The relationship between the SX score and the incidence of MACE was evaluated. Event free survival curves were generated by the KaplanMeier method and differences in survival were compared by using log rank test. The receiver-operating characteristic (ROC) curve was utilized to determine the cut-off value of SX score in order to predict 3 year clinical outcomes. A p value less than 0.05 was considered statistically significant. Statistical analyses were conducted using SPSS 22 for Windows (SPSS Inc., Chicago, Illinois).

\section{Results}

Fifty three acute STEMI patients who underwent primary PCI for ULMCA disease were enrolled in the study. Baseline characteristics of the patients are shown in Table 1. Mean follow-up period was $28.1 \pm$ 15.5 months (range, 0.17-61.5) and average age of the patients was $66.5 \pm 11.8$ (range, 34-87) years. Among the 53 patients 43 (81.1\%) of them were male and the remaining (18.9\%) were female. Increasing age was associated with higher SxS values, but this difference was not statistically significant. There was no difference between groups with respect to smoking status and family history of cardiovascular disease. Frequency of diabetes mellitus, hypertension, hyperlipidemia, congestive heart failure and cardiogenic shock was significantly higher in the high SxS group compared to low/intermediate SxS groups. Patients with high SxS were treated more often with diuretics, inotropic agents and glycoprotein IIb/IIla inhibitors, intra-aortic balloon pump support during hospitalization. Three patients required temporary pacing due to third degree atrioventricular block. Patients in SxS high group had higher length of hospital stay.

Angiographic findings of patients are shown in Table 2. Patients were treated with BMS only, DES only and hybrid stenting (DES + BMS). Stent type and diameter, balloon length and diameter, distal, ostial/ body LMCA disease and pre-dilatation and post-dilatation rates were not significantly different between the three groups. Multivessel

Table 1

Patients' clinical characteristics and medications.

\begin{tabular}{|c|c|c|c|c|}
\hline & Low SxS & Intermediate SxS & High SxS & $\mathrm{p}$ \\
\hline Male gender, n (\%) & $10(23.3)$ & $14(32.6)$ & $19(44.1)$ & 0.52 \\
\hline Mean age (years) & $62.86 \pm 16.3$ & $65.86 \pm 8.2$ & $69.04 \pm 10.3$ & 0.29 \\
\hline $\operatorname{LVEF}(\%)$ & $56.2 \pm 9.8$ & $55.1 \pm 7.3$ & $41.8 \pm 7.6$ & $<0.001$ \\
\hline Current smoker, n (\%) & $7(50)$ & $8(57.1)$ & $15(60)$ & 0.83 \\
\hline Family history of CAD, $\mathrm{n}(\%)$ & $5(35.7)$ & $4(28.6)$ & $10(40)$ & 0.77 \\
\hline $\mathrm{DM}, \mathrm{n}(\%)$ & $4(28.6)$ & $5(31.3)$ & $18(78.3)$ & 0.002 \\
\hline HT, n (\%) & $10(71.4)$ & $10(62.5)$ & $22(95.7)$ & 0.03 \\
\hline HL, n (\%) & $10(71.4)$ & $7(48.7)$ & $20(87)$ & 0.015 \\
\hline \multicolumn{5}{|l|}{ In-hospital medical treatment, $n(\%)$} \\
\hline ACE-I/ARB & $10(71.4)$ & $9(64.2)$ & $14(56)$ & 0.62 \\
\hline BB & $11(78.5)$ & $12(85.7)$ & $15(60)$ & 0.19 \\
\hline Glycoprotein IIb/IIIa inhibitors & $3(21.4)$ & $4(28.5)$ & $15(60)$ & 0.03 \\
\hline Statins & $8(57.1)$ & $7(50)$ & $13(52)$ & 0.92 \\
\hline Calcium channel blocker & $4(28.5)$ & $5(35.7)$ & $4(16)$ & 0.36 \\
\hline IV diuretic & $3(21.4)$ & $4(28.5)$ & $16(64)$ & 0.02 \\
\hline Inotropic drugs & $3(21.4)$ & $2(14.2)$ & $13(52)$ & 0.03 \\
\hline Clinic & & & & 0.002 \\
\hline Killip class $\geq 2$ & $3(21.4)$ & $3(21.4)$ & $14(56)$ & 0.035 \\
\hline Cardiogenic shock & $1(7.1)$ & $0(0.0)$ & $8(32)$ & 0.02 \\
\hline Length of hospital stay, (day) & $4.29 \pm 1.13$ & $4.36 \pm 1.08$ & $6.08 \pm 2.9$ & 0.03 \\
\hline Follow-up period, (day) & $923.1 \pm 325.3$ & $810.2 \pm 305.7$ & $886.5 \pm 606.1$ & 0.65 \\
\hline IABP & $2(14.3)$ & $0(0.0)$ & $8(32)$ & 0.04 \\
\hline Temporary pacemaker & $2(14.3)$ & $0(0.0)$ & $1(0.4)$ & 0.24 \\
\hline $\mathrm{SxS}$ & $18.42 \pm 3.2$ & $26.6 \pm 2.3$ & $36.38 \pm 4.1$ & $<0.001$ \\
\hline
\end{tabular}

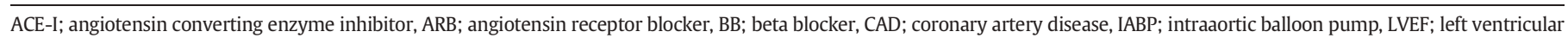
ejection fraction, and SxS; SYNTAX score. 
Table 2

Angiographic findings of the patients.

\begin{tabular}{|c|c|c|c|c|}
\hline & Low SxS & Intermediate SxS & High SxS & $\mathrm{p}$ \\
\hline Lesion location, $\mathrm{n}(\%)$ & & & & 0.73 \\
\hline Ostium & $4(28.6)$ & $4(25)$ & $9(39.1)$ & \\
\hline Shaft & $4(28.6)$ & $3(18.8)$ & $2(8.7)$ & \\
\hline Distal & $6(42.9)$ & $9(56.3)$ & $12(52.2)$ & \\
\hline $\begin{array}{l}\text { Number of diseased } \\
\text { vessel, } \mathrm{n}(\%)\end{array}$ & & & & 0.02 \\
\hline LMCA isolated & $4(28.6)$ & $1(7.1)$ & $4(16)$ & \\
\hline LMCA + 1 vessel & $10(71.4)$ & $9(64.3)$ & $12(48)$ & \\
\hline LMCA + 2 vessel & $0(0.0)$ & $2(14.3)$ & $9(36)$ & \\
\hline LMCA + 3 vessel & $0(0.0)$ & $0(0.0)$ & $3(12)$ & \\
\hline Predilatation & $9(64.3)$ & $11(68.8)$ & $10(43.5)$ & 0.23 \\
\hline Postdilatation & $4(28.6)$ & $5(33.3)$ & $8(34.8)$ & 0.92 \\
\hline Types of stent & & & & 0.49 \\
\hline BMS & $5(35.7)$ & $6(37.5)$ & $9(39.1)$ & \\
\hline DES & $7(50)$ & $4(25)$ & $5(21.7)$ & \\
\hline Hybrid & $1(7.1)$ & $5(31.3)$ & $8(34.8)$ & \\
\hline Stent length (mm) & $20.6 \pm 5.9$ & $23.3 \pm 7.5$ & $18.1 \pm 6.0$ & 0.07 \\
\hline Stent diameter (mm) & $3.01 \pm 0.48$ & $3.38 \pm 0.71$ & $3.02 \pm 0.49$ & 0.13 \\
\hline Number of stent used & $2.14 \pm 1.0$ & $2.71 \pm 1.4$ & $2.17 \pm 1.1$ & 0.33 \\
\hline Balloon length (mm) & $16.25 \pm 2.3$ & $14.8 \pm 3.1$ & $15.46 \pm 3.3$ & 0.61 \\
\hline Balloon diameter (mm) & $3.17 \pm 0.9$ & $3.02 \pm 0.9$ & $3.12 \pm 0.8$ & 0.92 \\
\hline
\end{tabular}

BMS; bare metal stent, DES; drug eluting stent, and LMCA; left main coronary artery.

coronary artery diseases were found to be significantly higher in the SxS group than those of in the low/intermediate SxS groups. An average of $2.3 \pm 1.1$ (min: 1 ; max: 6) stents were implanted per patient.

There was no difference in in-hospital reinfarction, TLR, and MACE rates in three groups, while patients with high SxS showed higher rates of mortality as compared to low/intermediate $\mathrm{SxS}$ patients.

During long term follow-up, $51.2 \%$ of patients with documented myocardial ischemia underwent diagnostic coronary angiograpy, of these $48.7 \%$ underwent PCI. There was no difference in MI rate between the three groups while ischemia-driven TLR was required more often in patients with high SX scores. Total mortality and total MACE rates were significantly higher in the SX high group compared with the aggregate Sx low and Sx intermediate group. In-hospital mortality and 3-year mortality rates of aggregate Sx low and Sx intermediate group and SX-x high group were $7.1 \%$ and $21.4 \%$ vs $40 \%$ and $56 \%$ respectively. In-hospital complications and 3-year follow-up results are shown in Table 3.

Figs. 1 and 2 show the cutoff value of SxS to predict the development of MACE and mortality. ROC curve analysis showed that the SxS exhibited $62.2 \%$ sensitivity and $62.5 \%$ specificity for predicting the development of MACE within 3-years after PCI at a cutoff value of 28.25. (AUC: $0.731 \mathrm{p}=.008$ ). SxS predicted mortality with a sensitivity of $70 \%$ and a specificity of $76 \%$ at a cutoff value of 31.25 (AUC: $0.675, p=$ 0.034). Kaplan-Meier estimated long-term survival rates were similar in

Table 3

In-hospital complications and 3-year follow-up results of the patients.

\begin{tabular}{lllrl}
\hline & Low SxS & Intermediate SxS & High SxS & $\mathrm{p}$ \\
\hline In-hospital & & & & \\
$\quad$ Death, n (\%) & $2(14.3)$ & $0(0.0)$ & $10(40)$ & 0.01 \\
MI, n (\%) & $1(7.1)$ & $2(14.3)$ & $3(12)$ & 0.83 \\
TLR, n (\%) & $1(7.1)$ & $2(14.3)$ & $3(12)$ & 0.83 \\
PTCA & $1(7.1)$ & $2(14.3)$ & $3(12)$ & \\
MACE & $4(26.8)$ & $2(14.3)$ & $10(40)$ & 0.24 \\
Long-term outcomes & & & & \\
Cardiac deaths, n (\%) & $1(7.1)$ & $3(21.4)$ & $4(16)$ & 0.01 \\
Myocardial infarction, n (\%) & $2(14.3)$ & $4(28.6)$ & $5(20)$ & 0.73 \\
TLR, n (\%) & $4(28.6)$ & $5(35.7)$ & $11(44)$ & 0.02 \\
PTCA & $2(14.2)$ & $2(14.2)$ & $10(40)$ & \\
CABG & $2(14.3)$ & $3(21.4)$ & $1(4)$ & \\
MACE, n (\%) & $6(42.9)$ & $9(64.3)$ & $11(44)$ & $<0.001$ \\
Total death, n (\%) & $3(21.4)$ & $3(21.4)$ & $14(56)$ & 0.03 \\
Total TLR, n (\%) & $4(28.6)$ & $7(50)$ & $14(56)$ & 0.25 \\
Total MACE, n (\%) & $6(42.9)$ & $10(71.4)$ & $21(84)$ & 0.04 \\
& & & &
\end{tabular}

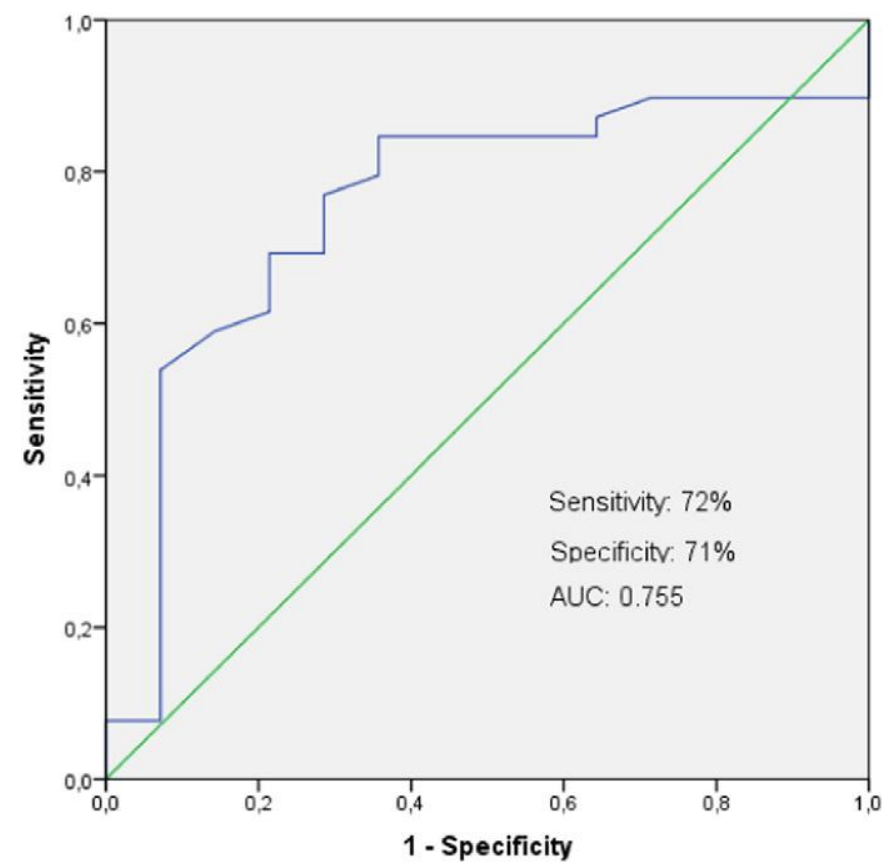

Fig. 1. Cutoff value of SxS for predicting the development of MACE.

the three groups (see Fig. 3). Three-year survival rates were 91.7\%, 78.6\% and $64.7 \%$ for SYNTAX low, intermediate, and high groups, respectively.

\section{Discussion}

Our results showed that SxS was a useful tool for prediction of inhospital and long-term outcomes in STEMI patients who were treated with emergency PCI to a culprit ULMCA lesion. The optimal cutoff values for 3-year mortality and MACE were 31.25 and 28.25, respectively. Our results support the hypothesis that high SxS indicates more complex coronary artery disease, worse clinical outcomes (worse Killip class, cardiogenic shock, hemodynamically unstable arrhythmias) and

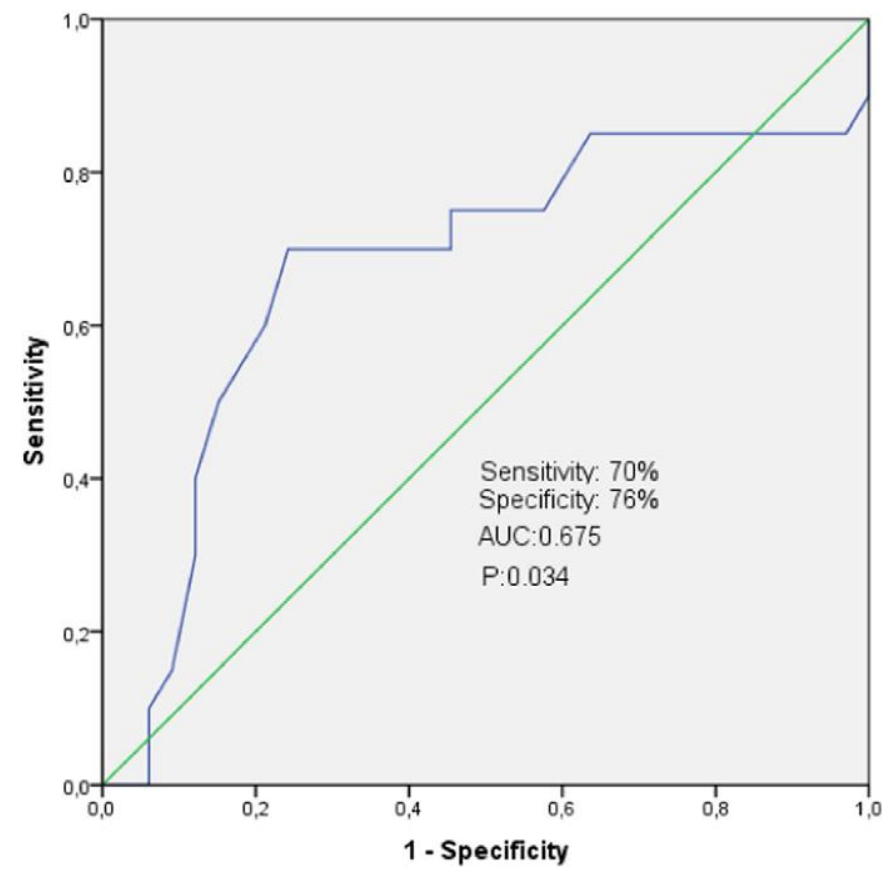

Fig. 2. Cutoff value of SxS for predicting the development of mortality. 


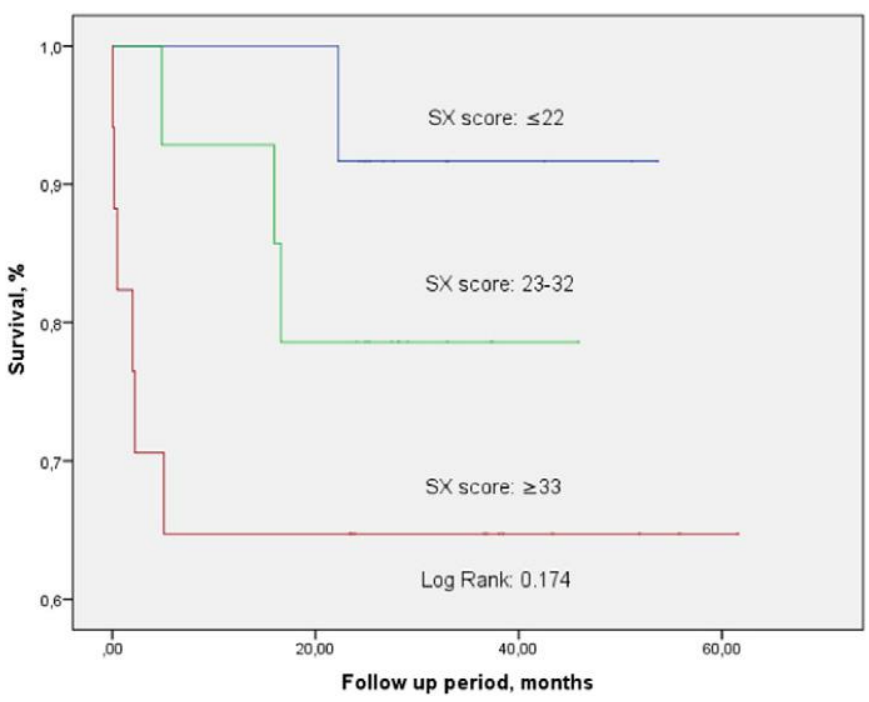

Fig. 3. Kaplan-Meier estimated long-term survival rates in the three groups.

multiple risk factors (diabetes mellitus, hypertension, hyperlipidemia, advanced age). Length of hospital stay, use of intravenous diuretics and positive inotropes, in-hospital MACE and mortality increase in parallel with the SxS. In our previous study, ${ }^{6}$ we showed that the SxS was an independent predictor of both in-hospital and long-term mortality in patients with acute STEMI who underwent primary PCI. Nozue et al. reported that score 26 was the optimal cutoff value for predicting one-year MACE in patients who underwent elective $\mathrm{PCI}$ for ULMCA disease. ${ }^{7}$ Another study showed that a score of 28 was the optimal cutoff value to distinguish patients at low and high risk of one-year MACE. ${ }^{8}$ Our results are in agreement with previous studies. SxS is an easily applicable angiographic scoring tool for grading the complexity of coronary artery disease. It assists in patient selection for interventional or surgical revascularization.

Acute MI associated with ULMCA occlusion is a clinically catastrophic event. These critically ill patients frequently present with cardiogenic shock or cardiac arrest. Patients undergoing primary PCI because of ULMCA culprit lesion and presenting with cardiogenic shock have high in-hospital mortality. ${ }^{9}$ The average estimated 30 -day all-cause mortality was $15 \%$ and $55 \%$ in patients presenting without and with cardiogenic shock, respectively. ${ }^{10}$ Complication rates are twice to four times higher in patients who undergo primary $\mathrm{PCI}$ in acute MI than elective PCI. ${ }^{11-14}$ LVEF, previous MI, door-to-balloon time, anemia, chronic renal failure and diabetes mellitus are independent predictors of mortality. TIMI and GRACE risk scores are used for risk stratification and prognostic evaluation.

In addition to several clinical risk scores, angiographic characteristics are used to predict both in-hospital and long-term prognosis. SxS has been developed aiming to grade the coronary lesions with respect to their functional impact, location, and complexity.

Consensus treatment guidelines continue to recommend CABG as the "gold standard" for revascularization of ULMCA lesions but note that $\mathrm{PCI}$ is feasible and may be a promising strategy in selected patients. ${ }^{15-17}$ Patients with ostial and trunk LMCA lesions treated with $\mathrm{PCI}$ have better outcomes than patients with distal lesions. ${ }^{16,17}$

Our in-hospital and 3-year follow-up results suggest that $\mathrm{PCI}$ is an acceptable alternative revascularization method to CABG when treating patients with low or intermediate SX scores. Our results are consistent with recent studies. Recently published EXEL-trial compared the efficacy and safety of PCI with CABG surgery in patients with ULMCA disease and low-intermediate anatomical SxS. In this study, although $\mathrm{PCI}$ patients had worse baseline characteristics (older age, male gender, COPD), 4-year mortality rate was significantly lower than that of CABG patients. The 4-year predicted mortality for PCI patients was $8.5 \%$ and $10.5 \%$ for CABG patients. ${ }^{18}$

High SxS is associated with increasing cardiac mortality, MACE and TVR at 3 years. Patients with high SxS have significantly higher 3 year mortality, MACE and TVR rates. Despite improvement in stent technology and operator experience, LMCA disease is still associated with high in-hospital and long term mortality rates and there is a need of development of new agents and clinical techniques to improve outcomes further.

\section{Limitations}

This was a single-center retrospective study, but the patients were prospectively followed up. In order to prevent bias, in-hospital and follow-up data were collected by different clinical investigators. Only $51.2 \%$ of patients underwent coronary angiography and clinical SYNTAX score of the patients was not calculated.

Another limitation was that the development of post-PCI contrast nephropathy was not evaluated.

\section{Conclusion}

The SxS has prognostic value in patients with acute STEMI undergoing primary PCI due to ULMCA disease. It may be useful in selecting the patients for the most appropriate revascularization strategy.

\section{Conflicts of interest}

None declared.

\section{References}

1. Giannoglou GD, Antoniadis AP, Chatzizisis YS, Damvopoulou E, Parcharidis GE, Louridas GE. Prevalence of narrowing > or $=50 \%$ of the left main coronary artery among 17,300 patients having coronary angiography. Am J Cardiol Nov 1 2006;98(9):1202-1205.

2. Sim DS, Ahn Y, Jeong MH, et al. Korea Acute Myocardial Infarction Registry (KAMIR) investigators. Clinical outcome of unprotected left main coronary artery disease in patients with acute myocardial infarction. Int Heart J 2013;54(4):185-191.

3. Serruys PW, Onuma Y, Garg S, et al. Assessment of the SYNTAX score in the Syntax study. Eurointervention 2009;5(1):50-56.

4. Can MM, Tanboga H, Karabay CY, et al. The treatment of acute myocardial infarction due to the occlusion of the left main coronary disease. Cardiol J 2011;18(1):77-82.

5. Sianos G, Morel MA, Kappetein AP, et al. The SYNTAX score: an angiographic tool grading the complexity of coronary artery disease. Eurointervention 2005;1(2):219-227.

6. Akgun T, Oduncu V, Bitigen A, Kirma C. Baseline SYNTAX score and long-term outcome in patients with ST segment elevation myocardial infarction undergoing primary percutaneous coronary intervention. Clin Appl Thromb Hemost Feb 42014 [Epub ahead of print].

7. Nozue T, Kamijima R, Iwaki T, Michishita I. Impact of SYNTAX score on 1-year clinical outcomes in patients undergoing percutaneous coronary intervention for unprotected left main coronary artery. Am J Cardiovasc Dis 2012;2(3):216-222.

8. Brito J, Teles R, Almeida M, et al. Predictive value of SYNTAX score in risk stratification of patients undergoing unprotected left main coronary artery angioplasty. J Invasive Cardiol 2011;23:494-499.

9. Montalescot G, Brieger D, Eagle KA, et al. GRACE investigators. Unprotected left main revascularization in patients with acute coronary syndromes. Eur Heart J Oct 2009;30(19):2308-2317.

10. Vis MM, Beijk MA, Grundeken MJ, et al. A systematic review and meta-analysis on primary percutaneous coronary intervention of an unprotected left main coronary artery culprit lesion in the setting of acute myocardial infarction. JACC CardiovasC Interv 2013;6:317-324.

11. Biondi-Zoccai GG, Lotrionte M, Moretti C, et al. A collaborative systematic review and meta-analysis on 1278 patients undergoing percutaneous drug-eluting stenting for unprotected left main coronary artery disease. Am Heart J Feb 2008;155(2):274-283.

12. Rodés-Cabau J, Deblois J, Bertrand OF, et al. Nonrandomized comparison of coronary artery bypass surgery and percutaneous coronary intervention for the treatment of unprotected left main coronary artery disease in octogenarians. Circulation Dec 2 2008;118(23):2374-2381.

13. Serruys PW, Morice MC, Kappetein AP, et al. SYNTAX Investigators. Percutaneous coronary intervention versus coronary-artery bypass grafting for severe coronary artery disease. N Engl J Med Mar 5 2009;360(10):961-972.

14. Shemin RJ. Coronary artery bypass grafting versus stenting for unprotected left main coronary artery disease: where lies the body of proof? Circulation Dec 2 2008;118(23):2326-2329. 
15. Lee MS, Kapoor N, Jamal F, et al. Comparison of coronary artery bypass surgery with percutaneous coronary intervention with drug-eluting stents for unprotected left main coronary artery disease. J Am Coll Cardiol Feb 21 2006;47(4):864-870.

16. Valgimigli M, Malagutti $P$, Rodriguez-Granillo GA, et al. Distal left main coronary disease is a major predictor of outcome in patients undergoing percutaneous intervention in the drug-eluting stent era: an integrated clinical and angiographic analysis based on the Rapamycin-Eluting Stent Evaluated At Rotterdam Cardiology Hospital (RESEARCH) and Taxus-Stent Evaluated At Rotterdam Cardiology Hospital (T-SEARCH) registries. J Am Coll Cardiol 2006;47:1530-1537.
17. Kim YH, Park SW, Hong MK, et al. Comparison of simple and complex stenting techniques in the treatment of unprotected left main coronary artery bifurcation stenosis. Am J Cardiol 2006;97:1597-1601.

18. Campos CM, van Klaveren D, Farooq V, et al. EXCEL trial investigators long-term forecasting and comparison of mortality in the evaluation of the Xience Everolimus eluting stent vs. coronary artery bypass surgery for effectiveness of left main revascularization (EXCEL) trial: prospective validation of the SYNTAX score II. Eur Heart May 21 2015;36(20):1231-1241. 